\title{
TIES THAT BIND: THE AMBIGUOUS ROLE PLAYED BY SOCIAL CAPITAL IN BLACK WORKING CLASS FIRST-GENERATION SOUTH AFRICAN STUDENTS' NEGOTIATION OF UNIVERSITY LIFE
}

\author{
L. Vincent* \\ e-mail: I.vincent@ru.ac.za
}

\author{
M. Hlatshwayo* \\ Master of Arts Graduate \\ e-mail: theodora.mlamuli@gmail.com
}

*Department of Political and International Studies

Rhodes University

Grahamstown, South Africa

\section{ABSTRACT}

In this article we examine the ambiguous role that social capital plays in first generation Black working class South African students' negotiation of entry into an elite higher education institutional environment. First generation student experiences have a particular relevance in South Africa where student enrolment increased by 193000 between 1993 and 2004, with many of the new entrants first-generation students. South African research on first-generation working class Black students has focused on the low proportion of these students who reach university at all and among those who do enter university, the significant number who perform poorly or drop out before completing their degrees. The role played by social capital (social networks, close friends, associations, clubs and other affiliations) in these students' experiences of negotiating their entry into university has been little explored. Using a combination of in-depth interviews, observation and hierarchical mapping with 28 participants at one historically white South African university, we exam here how social networks play a significant role in providing much-needed support to first generation Black working class students as they negotiate entry into the alienating terrain of a historically white university. The article argues however that when social capital networks are closed, tightly policed and inward looking, consisting only of individuals from similar backgrounds, such networks can serve to perpetuate disadvantage. In this context, the role of "brokers" - trusted individuals who are able to act as bridges to wider, more information- and resource-rich networks - becomes critical.

Key Words: first generation university students, South Africa, social capital, higher education, brokerage, trust 


\section{INTRODUCTION}

“... members are united by ties which extend deeper and far beyond the short moments during which the exchange is made.” (Durkheim 1933, 226).

"We were all friends, even though I didn't go to the places that they went. Because I don't have that kind of money. The people who I'm close to, are also the people who do not go to those places [laughing] and who don't base their lives on the things that they have and the places they can go to.” (Bontle).

Some 938201 students were enrolled in higher education institutions in 2012 with 78 per cent of those enrolled in full-time programmes being black students. As Scott, Yeld and Hendry (2007, 43) pointed out, "Black African students still constitute the majority of higher education drop-outs, frustrating efforts to address equity in the South African workforce as well as the country's critical skills shortage”. A significant number of these students are first-generation university students from disadvantaged socio economic backgrounds, who are categorised as being at a high risk of dropping out before completing their studies (Strydom, Mentz and Kuh 2010, 260). While all students must negotiate the challenges of the transition from high school to postsecondary education (Lara 1992; Rendon 1992; Rendon and Hope 1996; Weis 1992), research has shown that first-generation students have more difficulty making the transition and especially with meeting the academic demands and expectations required of them at university (see for example Terenzini et al. 1994). In a range of ways these students struggle to adjust and in the South African context, historically white universities have been found to be particularly alienating environments for black working class first generation students (see for example Sennett et al.’s 2003 study located at the University of Cape Town).

For some first generation students their failure to thrive at university is related not so much to academic under preparedness as to challenges of a more social and cultural nature: the university environment is experienced as alien, resulting in feelings of dislocation and an inability to focus on academic commitments (Allen 1985; Flemming 1984; Loo and Rolison 1986; Nettles 1991; Sennett et al. 2003). In this regard, Ishitani (2006) shows that the first two years of first-generation students' academic lives are the most crucial, determining either integration into the institutional environment, or continued feelings of exclusion and marginalization, and thus, subsequently, dropout.

Much of the extant literature on first generation university students has emerged from scholars focusing on the United States. South African research has examined how hegemonic institutional cultures play a significant role in alienating, particularly black and working class students, within especially the formerly white institutions which are often experienced as deeply 
exclusionary and marginalizing by these students (Allen 1985; Flemming 1984; Loo and Rolison 1986; Nettles 1991; Sennett et al. 2003, 109). While deficiencies of both cultural and economic capital have featured in the literature on first-generation student experiences, very few researchers in this field have looked at the notion of social capital in order to understand both what these students might lack or find difficult and how some are able to overcome aspects of their disadvantage and successfully negotiate their entry into university, including entry into formerly white universities.

“Capital” refers to resources possessed by individuals or groups that are capable at some future time of generating benefits. Social capital is one form of capital - other forms include economic, institutional and cultural capital. Social capital has to do with the idea, as Bartkus and Davis (2009, 1) put it, that "relationships matter". There are many ways of studying these relationships. One might, for instance, be interested in how large or dense networks of social relations are, or in their content: the norms, flows of information and values that animate them. One might be interested in what results from these networks and relationships: how do members benefit from their involvement in, or access to, these networks? And one might be interested in the resources that can accrue to individuals as a result of these relationships and how these resources or "assets" are able to help individuals and groups achieve their goals (Bartkus and Davis 2009, 2).

To invest in social capital is to anticipate certain "returns" (Lin 1999) which might not otherwise be available to a person (Coleman 1990, 302). Cooperation and trust are central to what makes such returns possible for members of a given network and cooperation and trust are in turn facilitated by relationships, shared values and norms. To build a network is to attain an asset that can generate future profits in the form of, for example, help, advice, support, information and opportunities. In this article we discuss the social networks that our participants - first generation black working class university students - describe having forged at university, and what benefits they have accrued from these networks. We are interested also in whether and how the social capital which they do and do not have access to might act as a limitation akin to possession of economic capital in a devalued or marginal currency that makes profitable exchanges difficult and costly.

\section{THE STUDY}

In this study we were interested in the role played by social capital in first-generation ${ }^{1}$ black working class university students' negotiation of the terrain of an elite, historically white, tertiary education environment. We hypothesized that these students - by virtue for instance of 
class, prior schooling, economic capital, language and "race" - may have found themselves, on entering an elite, historically white higher education institution, excluded from the most privileged social networks to be found there. Our first goal was to confirm or disconfirm this hypothesis by way of in-depth open ended interviews with 28 participants who met the inclusion criteria of being South African, Black, from working class origins and the first in their families to attend a tertiary education institution. These participants were asked about whether or not they experienced themselves as marginalised or "outsiders" in any way when they first came to university or if they felt comfortable and at home. The interviews confirmed that the participants experienced pervasive feelings of alienation and exclusion especially from the most privileged, powerful and dominant social networks that they encountered at university, whether these were in lecture theatres, sports and cultural societies or residences.

Our second hypothesis was that to the extent that the traditional or most privileged social networks were not available to these particular students, they might well be creating, accessing and taking advantage of alternative social networks which may or may not be helping them to overcome or at least more successfully negotiate their experiences of marginality and exclusion, disempowerment and alienation, in their everyday lives at the university. Employing the techniques of hierarchical mapping and in-depth interviews we aimed to describe the networks the participants are embedded in, as well as the networks from which they are excluded. Hierarchical mapping (see Antonucci 1986; Ajrouch, Antonucci and Janevic 2001) is a technique employed to gain a sense of the size and nature of a person's social networks. Participants map themselves in relation to three concentric circles starting with themselves in the middle circle ("You"), followed by people they are closest to in the next circle and then those they know but are least close to in the outer circle (McCarty et al. 2007, 146).

The participants were first-generation black South African working class students who were all in their third year of study at the time when the research was conducted. The rationale for choosing participants in their third year at university was that these students are by definition not part of the large percentage of first generation black working class students who drop out early on in their university careers. The participants therefore met the additional inclusion criterion of having found ways to succeed at university, their prior disadvantage notwithstanding. The sample was purposively constructed to include a diversity of firstgeneration students with respect to gender, language, faculty and geographic origin. Specifically excluded were those first generation black working class students who had attended former "Model C"2 schools or private schools, since the aim was to choose participants who possessed little access to privileged social networks on entering university. 


\title{
FINDINGS
}

\section{First hypothesis: that the participants would have experienced exclusion - by virtue for instance of class, prior schooling, economic capital, language and "race" - from the most privileged social networks encountered at university}

All the participants reported extreme feelings of alienation on first arriving at university. Participants described feeling "scared”, wanting to leave, crying every day, feeling "small”, lonely and isolated. The participants' sense of themselves as having had an inferior education compared to the more privileged students they encountered at university along with the unease that they experienced as a result of being in an environment dominated by English for the first time, meant that they were often isolated especially at first.

\begin{abstract}
“Because I wasn't confident with my English, I didn’t have a lot of friends. And then in school I didn't do well in physics. Like I had to rewrite to that thing. Then this person is from the US, just imagine a person who is a physics something, and then they are highly intelligent. Now you can imagine how fast they talk, plus with that accent. And imagine me who was from there.” [laughing] (Bontle).
\end{abstract}

"To begin with, in school I have never ever studied with white people before. And everything, even English was translated in Xhosa. I have never seen a computer in my life before. So I arrived here I was with my mother, and then she asked me whether I would be able to listen when there so many white people here. I just told her that I will make a plan.” (Ntokozo).

"I struggled to make friends ... cos you find that a person may be a Xhosa, but the English is good and they are not going to communicate with you in Xhosa ... they're going to communicate in posh English. Like everyone is speaking English and now you facing a challenge that you wake up in the morning, it's English, English you sleep, English all the time. So yoh it was hectic ... it was really a bad experience.” (Interview, Slindile).

"I actually cried the first day. I think the first three weeks of being here I would cry every day. It wasn't nice at all ... I actually called my mom and was like, I want to come home. I can't do this. I think I was more insecure about where I come from and all of that. I felt like everyone was just different you know, the white people and stuff" [laughing], "I was like yoh these people are very different from me ... so rich and all of that.” (Siya).

All forms of socialising require the use of communication. When language is experienced as a barrier, activities designed to facilitate social integration become another form of exclusion. While Ntokozo loves playing soccer and while his residence organised social soccer playing, his enjoyment was short-lived because of being “forced to talk in English”.

"I loved was soccer because that's the thing that made me talk a lot with other people. Because when we first arrived, we would all go play soccer at Kingsfield during the first week when we arrived. We would play well and everything would be fine. But unfortunately it was a very short 
period. But the problem was when we have to communicate with other people it was a challenge because then we'd be forced to talk in English. So you just sit aside and not communicate. Because I didn't trust myself with speaking in English.” (Ntokoza).

Whereas for those who feel at home in the culture of the institution, the residence dining hall might be a place to meet people and build social networks, for our participants the dining hall was often at first a place of exclusion and isolation from social networks.

"When I arrived in res, the first thing that made me realize that I want to go back home was around the time when it was time to eat. And then this this boy, Graham, who told me to grab a tray to eat, I was looking for a spoon and I just couldn't find it. I found a fork but I noticed that we were going to be eating rice, and I was wondering how the heck I was going to eat rice with a fork. So I was mostly left behind .... No no no you see the dining hall. The the challenge was the whole thing of eating rice with fork and knife - that was very unusual for me. I'm used to using a spoon and holding my meat. Things got really better when the seniors arrived, but when it was just first years, you would eat your food with your hands and the whole dining hall would stare at you as if they know that you're not used to using fork and knife.” [Laughing]. (Ntokozo).

"Uncomfortability? What can I say? Well the fact that we being told not to make noise whereas us guys were just having a conversation, and someone would come and say you making noise. Especially in the dining hall ... its where you [are meant to be] comfortable. And yet you find people telling us we are making noise. I think it's a bit rude. At the dining Hall, I was a very shy guy. I remember I used to sit alone because I felt like I couldn't fit in. I don't know these people, they come from affluent families so we couldn't share any conversation. So for instance someone would tell you ... 'when I went to England' and I couldn't relate to those experiences. So I kept to myself and I was like Sanza, you can't engage with these people because clearly you have different social settings and financial settings. So I just kept to myself cos I was like this guy from the township who has never been to a middle class setting. So I was always a reserved person, like I wouldn't engage in any conversation they were having. Even going out I would go to the [local] township instead of to [regular student hangouts].” (Sanza).

Like dining hall, eat with your knife and fork! I was like, Iyoh! Everyone is using that thing. Eh okay, how do we do this? Now I sat down, I folded my arms to watch [Nomonde] because she's confident with English and she has white friends. I'm just going to watch her with this thing and see how she eats it. Like how she uses that thing. It was like horrible at first, but then I enjoyed it. And then when I went home I do not use my hands.” [Laughing]. (Bontle).

Similarly whereas for those who are comfortable in the language of instruction, lectures might be a place to meet and socialise with other students, for someone like Ntokozo, to go class was to "immediately get lost".

"But when I go to class out almost immediately get lost as the lessons are conducted in English. And I was scared of asking because I didn’t have confidence in speaking English.” (Ntokozo).

"Yoh I was scared. I felt too small. ... And then I had that thing that now there was gonna be a white person standing in front of me, teaching me which I was not used to that. And then I had that thing whereby I wonder if I'm gonna make it. Because I'm not used to being taught in English, because the lecture will be in English and whether you understand that or you don't understand 
nobody cares.” (Sindile).

"I can have a small self-esteem coming from where I come from. Knowing Rhodes, most kids here come from very good backgrounds, they're very rich. Black or white, they're very rich. They come from good schools.” (Vusi).

Social class operates as a powerfully felt exclusionary mechanism. The ability to participate in, and enjoy, social events is often premised on prior experiences and present financial resources which our participants lacked. As a result the networks and friendships that are built through these social events were not available to these participants.

"I did not have a laptop. I didn't have the phone that can chat, I had that green screen thing, it had sellotape around it .... So if there was the res ball, I wouldn't go because I wouldn't have that outfit. So people who could go there I wasn't close to.” (Bontle).

Class exclusion operates on multiple levels illustrating how different forms of capital economic, cultural, institutional and social - produce one another. For instance social networking happens through technology and social media, requiring both the know-how to operate computers and smart phones and access to these resources themselves.

Rituals designed by the institution to help ease new students’ process of settling in can have the opposite effect because they selectively expose people to public scrutiny in ways that are shaming and therefore far from being enjoyed, have to be endured.

"That part of serenading, ${ }^{3}$ it really made me feel uncomfortable because in serenading you have to wear nice pyjamas, and I did not have those things. So they used to be times I'd lock myself in my room. Like no ways everyone is looking nice and I feel like I don't fit in with this group you see. So yeah that part, I did not like it because I felt like it was only for certain people so as a result I wouldn’t participate that much in those activities.” (Slindile).

“Ya! My fist serenade I was very uncomfortable. Because I didn’t even know what it meant to serenade anyone. And I had to go there and do this thing. And we were made to go there in our boxers. And no shirt on so I was very uncomfortable. But I sucked it up and did as I was told to do.” (Sanza).

For many of these participants, one of the key markers of their identity is having been brought up in culturally and socially homogenous circumstances - apartheid geographies are still very much felt in the upbringing of these students so that they have grown up with people who are similar to themselves in terms of culture, race, language, class, religion, values and outlook. In contrast it is a mark of the privilege of students who attended private or former Model C schools that their experiences are often more cosmopolitan. The latter will have attended school with people of different colours, religions, ethnicities and language backgrounds. This makes their 
social adjustment to university life less challenging.

“At res ... just the difference in the variety of people, the culture ... like Indians, I didn't know that they had stuff in their rooms. Those pictures and those symbols, you know. So I got to appreciate and accept people for what they are, and not judge them.” (Bontle).

"Even this thing, of people who are gay - it was my first time seeing and talking to them, whereas in high school I didn't even get along with them. We were like gay people must walk with gals and you don't want anything to do with them. But when you get here you realize that this thing is normal, they are people as well.” (Tylar).

Participants also reported encounters with overt racism which excluded them from certain kinds of experiences and relationships. Sexual relations across lines of colour, for instance, are often closely policed. Bontle, for example reported dating a "Hindu” but "it only lasted three days!" because "he had a cousin who was in the same class as me, and she didn't like the fact that I was Black and he's with me”. An early sense of open possibilities often gives way to an awareness of barriers and undercurrents of surveillance thus limiting the pool of candidates that might be available in any given setting as potential members of a person's social network. The point is that these limitations are not felt everywhere and equally.

"As years went by the dynamics started to manifest themselves. As you know, Us and Them. I remember whenever there was theft in res there was always that one white person who would [ask me] 'do you have any knowledge of what happened?' .... And ... they never go to other white people and ask them, 'Do you have any knowledge about this?' They always come to us. I've learned to live with it. It’s a way of life. Being Black means you always a suspect.” (Ntokoza).

In an academic environment to struggle academically is often very isolating. The shame of academic failure can mean that a person tries to hide what they are going through and cuts themselves off from the mainstream academic networks where people discuss grades, tests and study methods.

"My first test in Zoo so I got like 13\%! Do you know how painful it is when you know that in high school you did so well and you come here and your first test you get 13\%. Because you didn't hear a thing. Okay they were talking about dinosaurs, people who are from backgrounds where you exposed to [that] stuff then you would get it. I didn't get it. It was the first time that I actually saw like a microscope, cylinder, all those lab things.” (Bontle).

"So I was mostly left behind. ... I didn't even know what lecture or where to find it when I arrived. What I was gonna do, when I was doing it and even where I was going to do it including the times of the lectures I was so confused ... I wanted to leave this place. I didn't know anything about a computer. I remember it was such a challenge to even move just a mouse.” (Ntokoza).

"So when you get here, there is a computer in front of you, and you feel like they are demanding too much of you. And Accounting was very different from the way it was taught in high school. 
You are arriving in a lecture, and there is so many of you. In grade 10 to grade 12 we were less than 40 in class. So a teacher would give you individual attention. And you get it, and would communicate well and thrive in that class. And now you come here and we are over 200 and something in Accounting. And then the lecturer would come and lecture, and you feel like you're losing out on something, and before you know it you're left behind. In high school you could be able to speak to your teacher, they were Xhosa and would communicate in the same language. For instance, you would say no teacher this and this I didn't understand it, do you mind repeating it, and they would repeat it back to you in Xhosa. So when you get here, everything is different, it's like the tempo is very different.” (Tylar).

Our participants thus confirmed that they experienced university life as very alienating on multiple levels. Their exclusion related to their prior experiences, their prior schooling, cultural and class background, to racism, language, social rituals that are designed to promote inclusion but which are themselves raced and classed and which served to perpetuate their sense of being isolated from the mainstream. Given this, we were interested, next, to find out what they did to foster their own networks, who their friends and acquaintances were and if, as Barkus and Davis argue (2009), relationships really do matter, what role the relationships they did have, rather than only those they did not have, played in their lives at university.

\section{Hypothesis two: Successfully building and utilising social capital plays a role in how some first generation black working class students manage to overcome their challenges at university}

"I could do Honours because of the relationship I had with him. He referred me to relevant places and as such I began to understand the stuff I needed to understand. Now he’s doing his Honours and I'm still doing my undergrad so I look up to him and I go to him for advice. Whenever I have troubles say for instance I want to apply for bursaries or any applications here in the Department I would go to him and ask for advice. He is always there to help.” (Sanza).

“There's this guy, Zima, eish, he’s been helping me out in everything, and he's a very smart person, not really smart but he's very hard-working and that's what I learned from him, to work hard. And whenever you get that $48 \%$ back, don't be like 'oh my goodness I am failing' and stuff. Just keep on pushing. So he's just one of those people that taught me that and he is just very positive about everything. And whenever I go to him like I don't understand, he knows that I panic, like I don't understand this, he'll be like no it's easy and I feel like that line from him just makes me so calm cos I know that if he did it I can do it as well.” (Siya).

For all the challenges that they reported, our participants were, at the time of being interviewed, in their third year of study. They had found ways of surviving and even thriving at university. Given their exclusion, marginalisation and isolation from many of the mainstream social networks at university - formed through serenading, gym membership, vocal participation in 
lectures and tutorials - how, if at all, we wondered, do first generation black working class students build networks and accumulate social capital in a middle class, predominantly English speaking academic institution.

In a very early usage of the term, James Coleman (1988) employed the concept of social capital in an analysis of high school dropouts, arguing that Catholic school students did better academically, in part as a result of strong community bonds. Networks only count as social capital if they contain, latent within them, appropriable resources. It is clear that although their networks consist of the relatively disadvantaged members of this particular setting, the participants' experience is that they are resource-rich and provide considerable benefits. This brings us to our second hypothesis: that the ability to build and utilise alternative repositories of social capital can play a role in determining whether new entrants into traditional universities survive or become the early drop outs and failures that the statistics predict for this demographic. The social capital literature suggests that a number of features must be present for social networks to act as a form of capital for the members of a network. Here we discuss three which emerged as prominent thremes in the qualitative interview data generated for the study namely "trust”, “closure” and "brokerage”.

\section{TRUST}

Individuals create social capital when they build networks of people on whom they can rely and whom they can turn to for help when it is needed. Often these networks consist of people who share values and experiences which helps to explain why individuals within them may be willing to defer their own interests in order to act as a resource for others in the network who might be facing challenges. First generation students often turn to other first generation students when they need help because it is these students whom they feel they can trust. The concept of trust is much discussed in the social capital literature. In an early treatment of the subject, Mayer, Davis and Schoorman (1995) argued that rather than being dispositional alone, trust is a feature of relationships. To trust someone we have to be able to rely on them to do what they say they will do and we have to be able to count on their intentions towards us being benevolent. It is one thing for these features to emerge as a result of the intimacy and close contact of personal friendships but it is more difficult to explain why and how they emerge among people who do not know each other well and have no formal ties or obligations to one another.

Bartkus and Davis $(2009,8)$ argue that "we are drawn to those with whom we share similarities of background, experience or values”. Our participants found themselves in an environment in which they are a noticeable minority - marked by their accents and difficulties 
with English, academic challenges, placement in extended studies programmes, and discomfort with the dominant practices and values of the institution and its more privileged members, both black and white. Unable to trust those with whom they have little in common to understand their challenges without scorning or patronising them, they turned to role models and mentors whom they see as having gone through similar challenges. They are able to trust these people not only because of who they are but because they believe that these people have the tools to deal with the specific problems that they, the participants, have, since they have themselves had these problems and successfully negotiated them.

"Afro is one of my seniors I found here when I arrived. Plus he is one of the people who told me that he too came here without knowing a thing about a computer, so he was one of the few people that was advising me. So he was the one telling me and advising me that I will be fine. Because he kept reminding me that he was also like me when he first arrived and he is still here so I mustn't worry about it. Yeah Sviwe was tutoring computer science but he was tutoring another group. So the was this team called F11, it was a team from the foundation class, so that's how we met each other. He is also a product of the foundation program. He's doing Bcomm 3rd year now. He used to tell me how it was like for him when he first arrived, and I too would tell them about my experiences as well. Especially how I'm struggling and how hard it was for me. But he assured me that I was gonna be okay, and that whenever I was facing any problems he would be there for me. Even now I still utilize him whenever I have challenges.” (Ntokozo).

There's this guy from KZN. His name is Lucky. We were on the same level ... like my problems would be similar to his problems because we complaining about the same thing, everything was the same; we used to share our problems. Even though we are from different places but we did relate on most of the things. Because we were also from the same class. You know if you in the same class these guys understand. And then me and him were behind. Like I don't know we were not fast learners. So he would see that this guy doesn't understand, and then I'll be okay I see that this guy doesn't understand. Because we used to be asked questions you know, and then we wouldn't answer, me and him. And then I went to him to ask him, hey bra, why wouldn't you answer? And then he said, 'hey brah, I'm so ashamed'. I don't understand sometimes. His problem was also English, not understanding. Because when you come here I think they assume that you all from the same level schools. But yeah we did relate a lot, and we did share the same story. And Lucky he was just like me; he was just like me.” (Lundi).

"I've come to realize that we are similar in so many ways, it's easy to hold onto a friendship where these common principles and a common ... we're in the same type of life or class or so it, it makes me feel really comfortable like she made me feel, comfortable to be friends with. And maybe because with her I didn't feel inferior, I didn't feel like, when I was with her I felt like myself. I didn’t feel less of myself, as like I often felt with other people.” (Mariah).

The participants thus described using social markers - accent, language, class, background - to identify what might be termed their "trust candidates". Essentially this means that first generation students often build networks consisting exclusively or primarily of other first generation students. As Ntokozo puts it, they are all "products of the foundation" - a reference to the extended studies programme, a four year degree programme designed for students who 
would otherwise not be accepted into the university on academic grounds. Because first generation students look for social markers as a means of identifying trust candidates with whom to build a social network, their networks end up relatively homogenous and comprised of similarly disadvantaged members - people from poor backgrounds, whose first language is not English, whose prior schooling often ill prepared them for tertiary education and who are members of extended studies programmes.

Putnam (2000, 22) suggests that there are two types of social networks: bridging (or inclusive) networks and bonding (or exclusive) networks. Bridging networks are outward looking, are often made up of individuals from diverse socio economic backgrounds and are characterised by weak ties with members lacking a shared identity, common ideas, values or beliefs - members are united instead by a common cause or shared objective (Granovetter (1973, 1360). Bonding networks in contrast are characterized by, and reinforce, exclusive identities, with their members sharing similar identities and common beliefs (Granovetter 1973, 1360). Networks established by first generation students as a means of coping academically and socially at university often evince these bonding network characteristics: in response to alienation, first generation black working class students establish and attempt to sustain strong exclusive networks made up of people who are similar to themselves and dissimilar to the privileged majority encountered at university. While characterized by strong ties these networks are weak from a social capital point of view because they are inward looking, designed to shield their members from contact with other networks which might offer information, resources and forms of support that members, because of their strong, exclusive, inward looking ties, then become cut off from.

\section{CLOSURE}

In the social capital literature (Bourdieu 1986; Lin 1999; Lin and Bian 1991; Burt 1992; 1997; 1998; Marsden and Hurlbert 1988; Campbell, Marsden and Hurlberg 1986; Boxman, De Graaf and Flap 1991; De Graaf and Flap 1988; Sprengers, Tazelaar and Flap 1988; Volker and Flap 1996; Portes and Sensenbrenner 1993), norms and sanctions play a significant role in the creation and maintenance of "closure" in social capital networks. Closure has to do with connections and sharing being seen to be finite or bounded and therefore all the more trustworthy and valuable. Norms and their accompanying sanctions are significant in that they help with the formation of trust networks and their protection. These networks have within them, various means with which they can sanction an individual thus ensuring that they meet the expectations of the network, can be trusted to perform reciprocal obligations and are 
trustworthy. When a network is governed by norms of reciprocity that are subject to surveillance, this increases the trust that members have in one another and this then allows for the emergence of benefits such as sharing information, lending each other resources, and performing reciprocal and mutually beneficial favours such as assistance with essays and tutorials. These activities further strengthen network connections, and close and consolidate connections between the members (Coleman 1988; Putnam 2000).

In closed networks, the behaviour of members is closely monitored so that group norms are maintained, while also policing and monitoring the flow of information between each other. Rather than the individuals in a closed network being seen as resourceful social capital connections for one another, the emphasis becomes one of ensuring conformity to group norms and the fulfilment of network obligations. Sanza for example comments on his friendships with Ntuthuko and Xolile respectively, and how similar their socio-economic backgrounds are:

“uNtuthuko he's my intellectual friend. He's an interesting man in the sense that he's from the rural areas and usually stereotypes that we have about people from the rural areas is that they have no infrastructure so their education is bad, they have issues with the medium of instruction. But uNtuthuko when I met him he proved me wrong. That that is not always the case. He is as intellectually capable as I am. So I look up to him academically. ... uXolela is also from the rural areas. He's my res mate. And my friend as well. He's the guy with whom I share my social background. Because socially we from similar backgrounds. We went to Township schools to together. So he is one of the guys with whom I relate with say identically. So I consider him to be my closest friend as well. We met in my first day when I first got to res. I remember we had to introduce ourselves. He's the only one who rose up and said my name is Xolela and I' $m$ from the Eastern Cape, I won’t tell you about my school because you will never know it.” (Sanza).

Whereas members of privileged class networks might gain instant mutual recognition by introducing themselves as coming from a particular school, Xolela indirectly references this commonly traded form of cultural currency and his own lack of it because his school is one that the listeners in this milieu "will never know". For Sanza, both Ntuthuko and Xolile share with him a poor background and the fact that they come from rural areas and schools that no one has ever heard of, make them accessible to him, and provide the basis for the formation of a trusted network between them. Their identification with one another facilitates mutual respect and admiration. For Sanza, Ntuthuko becomes the "intellectual friend" whose life acts a counternarrative to the traditional stereotypes of what people from the rural areas are like.

But as is best expressed by Sanza's recollection of when he heard Xolile confirm his insignificance in front of the residence by not naming the school he attended, this friendship with its mutual recognition is a closed one. The members have no expectation of being recognised as anything other than inferior by those who do not share their background. Sanza's 
recognition of Ntuthuko and Xolile is rooted in a shared struggling background and poor schooling which ensures that their connection is characterised by strong inward looking ties that although strengthening their bond with one another, disconnects them from accessing other (richer and more resourceful) networks of the privileged, and further entraps them in these struggling and marginalised networks.

Sandy's experiences with her friends moreover, point to the policing and monitoring of one another's behaviour that happens in these closed networks:

"I had friends that I knew, it would be three of us, and we would just sit by ourselves. And we wouldn't go to any other people, and at some point I was like no man, these people. I would get my tray by the door [in the dining hall] ... I would look around, who do I feel like is clicking in my heart right now, 'Oh let me sit in that corner there, laughing making a noise, let me go sit there'. And my friends would give me the eye, Sandy why didn't you tell us that you gonna leave, we were waiting for you, we only ate the two of us, where were you? Why did you decide to sit there on the other side? And I'm like, okay I just saw them sitting there, and thought you will be coming. I just chatted with them and actually enjoyed myself.” (Sandy).

As much as Sandy's network of friends who share her background are a resource for her to draw recognition and comfort from, her network is also, as Burt $(2005,107)$ has suggested, self-monitoring and policing. Sandy's foray to "the other side" of the dining hall, both literally and socially, becomes a sanctionable act that goes against the expected conduct of the network, resulting in Sandy needing to account for daring to bridge the network and interconnecting with other much more advantaged networks whose resources and denser connections may hold the potential for her to enhance her own capacities for succeeding at university. Thus the group itself becomes Burt's omnipresent hydra eyes that are always looking to detect and police nonconformists. In this way, social capital can become a limitation on the individual's actions and availability - on the choices that a person can potentially make. For Sandy, this is seen in how her limited, inward looking strong ties with her friends, begin to work against her in that they start to restrict and sanction her attempt to transcend the boundaries of her network - and hence of her social position.

Closed networks therefore have limitations when they constrain the potential of their members in contrast to more outward looking networks where ties, as Granovetter notes, may be weaker, but which are able to attract different individuals from diverse backgrounds and combine with richer and interconnected networks that an individual can have an access to and withdraw benefits from (Granovetter 1973). Thus networks characterised by weaker ties (members are more distant from one another and the sense of belonging to the network is not as close) can nonetheless be greatly beneficial to individuals, helping for example in the 
diffusion of ideas, public information and the offering of technical advice (see Rogers 1995; Constant, Sproull and Kiesler 1996). Network poverty leads to the need for "brokers" who are able to connect first generation students with other resourceful and richer networks and connections that could help them negotiate their marginality at university. "Brokers" can help overcome the constraints of closed networks of disadvantage which are limited in the quantity and nature of capital that they can offer their members.

\section{BROKERAGE}

"The culture of the university systematically excludes those that are different to it. For your humanity to be respected you have to assimilate to the institutional culture of the university. A Black student from a township or rural parts of South Africa - particularly from the Eastern Cape - is constantly told that you are backward because you have a bad fashion taste, you are computer illiterate and you cannot speak English properly, in a nutshell you are not good enough .... The student then embraces the inferiority complex, 'I am not good enough' ... 'only those from a particular class can make it in this place’....” (Ntuthuko).

First generation students like Ntuthuko experience an "inferiority complex" and feeling "not good enough" - an overwhelming experience of lack which fellow social network members can do little to ameliorate since membership of first generation networks is based on recognition of shared perceived “deficiencies” as defined by the dominant culture of the university. Describing how they negotiate this alien environment, the participants referred to ways in which they sought belonging and acceptance in what have been termed "networks of poverty" - that is to say, networks that are under-resourced, are themselves marginal and therefore lack interconnections with well-connected and rich networks (Perri 6 1997, 10-11). These networks are characterised by strong ties rooted in for instance cultural identity or language, but they are inward-looking and reinforce exclusive identities. They are networks of, and at, the margins. Although enabling first-generation students to find belonging and acceptance in an alienating and marginalizing environment, their membership of these networks reinforces their "firstgeneration" status, and separates them from the privileged networks of those in possession of the currency of the dominant groups. This results in first generation students being trapped at the margins, having to resort to networks that lack significant (social, economic, cultural) capital in a currency that can be exchanged for advantage in their present institutional setting.

For these students the role of network brokers or intermediaries with other networks becomes a critical source of access to forms of social and cultural capital that their own network would not in itself be able to provide. The significance of what one could call "first-generation brokers”, that is, individuals who are first-generation students themselves and who have 
experienced marginality and social dislocation at university, and who act as intermediaries with information- and resource-rich networks, featured prominently in the interview responses of the participants in the present study. Participants cited these intermediaries or "brokers" as having played a significant role in enabling them to negotiate their feelings of marginality and making them feel like they belong and can make it at university.

Joseph Galeakiewicz and Karl Krohn (1984) define brokers as transmitters who send and receive information from the different networks that they are embedded in. Brokers receive information from one network and have the ability to control and send that information to other networks. Peter Marsden (1982, 202) refers to brokerage as a process "by which intermediary actors facilitate transactions between actors lacking access to, or trust in, one another”. Brokers are resourceful and innovative in being able to seek out information and opportunities that benefit the network that they belong to. Bontle, commenting on her mentoring of first year students explains how her own shared experiences with people in her network provided her with the insight which enabled her to more effectively play the role of broker to facilitate members of her network becoming "varsity girls" - a role which she sees herself as having arrived at and therefore able to shine a light on because of what she herself has been through.

\footnotetext{
"Because we not only speaking about school life, we also speak about life, they didn't cope with a lot of workload. We [are] used to it by now, we like okay bring it on. And now they're not handling it well. So I was just giving them pointers here and there because they are not attending some of the sessions so I only have a few girls instead of everyone. And then we also have the WhatsApp group, we communicate then people just come in, and see what can we do with us and then some of the girls [are doing] the same degrees. But it's a great experience, I see them grow to be being varsity girls and that's nice to watch.” (Bontle).
}

Bontle is able to act as a bridge for other first generation students, linking them with the various knowledges she has acquired - not only academic but also social and emotional - which have enabled her to negotiate her own marginality and succeed in becoming "a varsity girl”. The mentoring programme becomes the platform that she utilizes to give the first generation students in her network the necessary information and support they need to themselves negotiate university life. Technology ensures that Bontle's connections with her students do not always need to be re-enforced through physical contact. This allows her to potentially extend her brokerage agency through taking advantage of social media platforms that allow her to both access resources and distribute them to her mentees.

Pinky and Meli, now employed graduates, comment on why at university they decided to act as mentors to other students, despite neither being rewarded nor compelled to do so. Their own experiences of being first-generation students, socially dislocated from the university and 
feeling alone, played a significant role in them reaching out to other first-generation students and helping them.

"I think what made me keen to always try and assist other students in my dining hall was because of my own experience when I got to university. Although I had come here with four of my close friends from high school, adapting to the new environment was very difficult. This was particularly because we were all put in different residences that were very far apart. As a result of this we grew quite distant and varsity started to feel like a very lonely experience. This all changed because of Khanyile, who was the senior student at Canterbury in my first year.” (Pinky).

"When I started first year I wished there was someone who would have guided me and gave me advice on how university life was like, which courses to take, what should I do to cope, what challenges laid before me and other things like that. But unfortunately when one is the first person to go to university in the family, one does not have that privilege. You just have to let experience teach you. I mean the whole university thing was just nerve wrecking, especially from someone coming from a rural school. And this is how other people in my situation have felt. Even in res there was not much support for people like us, no one really understands you and where you coming from. Most of the senior black guys were from Model C schools. It was rough to say the least. Hence I tried to give as much as I can to these guys.” (Meli).

In this type of brokerage the broker and the network members identify with one another, they are part of the same network (Gould and Fernandez 1989, 92). In this form of brokerage network members benefit from the experience and know-how of a local broker who is seen as "one of us”. A different form of brokerage occurs when the broker is a member of different networks from those who benefit from his or her brokerage. While these types of brokers may or may not have their roots in similar identity positions they are now embedded in wider and power powerful networks. Mr. Makatsa is not only helpful and empathic but also, importantly, as Mariah puts it, is an example of someone who has "made it away" helping to demonstrate to those who might otherwise feel trapped at the margins that "it can happen".

“Mr. Makatsa. I think in my extended studies he's my favourite. He is because he understood my computer situation and he was my computer science lecturer. So he could allow me to be me and to be faulty. The way he was patient with me always asking, what is this? what is that? what is this? what is that? and he always motivated us. You know I'm very big on positive things like, I believe in positivity more than anything. So him seeing great in us kinda also helped me and he'll always tell us about people who made it away in our situation. You know so that also kinda helped me see that it can happen.” (Mariah).

Brokers have access to, and are able to use, richer networks and connections, information and resources, and they are able to offer these to members of more impoverished networks with which they identify or empathise. Strong ties may limit members of a network because commitment to the network is valued over the individual's personal growth and development; 
and because the network lacks resources that members sorely need. Thus there is a need for first-generation students, to connect with a broker, one who acts as a "middleperson" who can link them to the resources that they lack without their having to sacrifice their position as a recognised, trusted insider in their own network, and all the benefits of comfort and support that accrue as a result of this status.

\section{CONCLUSION}

Social capital plays an ambiguous role in black working class first-generation students' negotiation of university life. Since they do not have easy access to the most privileged and resource-rich social capital networks at university, our participants described creating inward looking networks, made up of individuals with similar identities, personal stories and family circumstances to themselves. On the one hand there is much to be gained from their close connections to others who are like them. Shared identities foster trust and strengthen network ties, resulting in benefits of support, understanding and comfort for members of these closed inward-looking networks. While weak from the point of view of social capital resources, the strong ties in these weak networks help their members to know that they are not alone, and that there are people at university whom they can trust. This plays a significant role in their being able to cope with the challenges that often come with their "first-generation" student status.

Trust plays a significant role in the creation of networks. Our participants described drawing on various markers such as language and membership of extended studies programmes, to enable them to find and recognize trust candidates. These forms of mutual recognition help first generation students with network building because for these students, reaching out is a risk, given their vulnerability and marginality in a higher education context dominated by English, by a colonial history and populated mainly by the socially privileged. In looking for trust candidates they must take care not to expose themselves and risk being further humiliated.

On the other hand their failure to build significant bridges to other, more resource-rich, privileged networks, beyond their own particular group, means that individuals like these might miss out on the potential benefits of being able to see beyond the vantage point of the group and to connect to other ways of doing things, thus narrowing the alternatives that are available to them. The closure of first-generation networks can work to exclude members from the richer and denser connections that are potentially available to them and which may aid their advancement and serve their interests. What Burt $(2009,60)$ calls the problem of "too much closure" he describes as "a hardened social shell that forms around the community, protecting 
them from ideas not invented there" $(2009,62)$. Recognition results in the creation of strong inward-looking ties. As much as these ties are a source of comfort and solace, their drawback is that they can become binding or constraining: they risk reinforcing the marginality and location at the periphery of the institution of those who share these ties/binds. They are networks of poverty and the benefits that they are able to confer on their members are always going to be limited.

The challenge for building more equitable institutional cultures suggested by this is that we need to think of ways in which the trust and collaboration that emerges in these closed networks is respected and understood while at the same time realising that these features are born of a wider sense of isolation that these students experience. For good reason, they find it difficult to trust the more formal networks and resources that are available to them and also to broker bridges to other communities of practice. Greater institutional recognition and credence needs to be given to the myriad informal ways that brokers act to connect members of marginalised networks to resources, opportunities, information and people - all of which can play a significant role in ensuring that these students succeed. Knowing that brokerage often does not simply emerge organically or automatically but that it is significant when it does means that universities can take concrete steps to encourage staff and senior students at various levels of university life to play this role.

\section{NOTES}

1. The term "first-generation student" refers to students whose parent(s) or guardian(s) do not possess a postsecondary, tertiary qualification (Pascarella et al. 2004, 249).

2. Relatively privileged public schools that were designated whites-only under apartheid.

3. "Serenading" is a practice in the university residences which involves first year students of one gender singing to members of another residence of a different gender, often in the early hours of the morning, wearing pyjamas.

\section{REFERENCES}

Antonucci, T. C. 1986. Hierarchical mapping technique. Generations 10(4): 10-12.

Ajrouch, K. J., T. C. Antonucci and M. R. Janevic. 2001. Social networks among blacks and whites: The interaction between race and age. Journal of Gerontology: Social Sciences 56B(2): S112S118. DOI: 10.1093/geronb/56.2.S112.

Allen, W. R. 1985. Black student, white campus: Structural, interpersonal, and psychological correlates of success. Journal of Negro Education 54(1): 134-147.

Bartkus, V. and J. Davis. (Eds.). 2009. Social capital. Cheltenham: Edward Elgar Publishing.

Bourdieu, P. 1986. The forms of capital. In Handbook of theory and research for the sociology of education, ed. J. Richardson, 241-260. New York: Greenwood.

Boxman, E. A. W., P. M. de Graaf and H. D. Flap. 1991. The impact of social and human capital on the income attainment of Dutch managers. Social Networks 13(1): 51-73. 
Burt, R. S. 1992. Structural holes. Cambridge: Harvard University Press.

Burt, R. S. 1997. The contingent value of social capital. Administrative Science Quarterly 42(2): 339365.

Burt, R. S. 1998. The gender of social capital. Rationality and Society 10(1): 5-46.

Burt, R. 2005 Brokerage and closure. An introduction to social capital. Oxford: Oxford University Press.

Burt, R. 2009. Network duality and social closure. In Social capital, ed. V. Bartkus and J. Davis, 3965. Cheltenham: Edward Elgar Publishing.

Campbell, K. E., P. V. Marsden and J. Hurlbert. 1986. Social resources and socioeconomic status. Social Networks 8: 97-117.

Coleman, J. 1988. Social capital in the creation of human capital. American Journal of Sociology 94: S95-S120.

Coleman, J. S. 1990. Foundations of social theory. Cambridge: Belknap Press of Harvard University Press.

Constant, D., L. Sproull and S. Kiesler. 1996. The kindness of strangers: The usefulness of electronic weak ties for technical advice. Organization Science 7(2): 119-135.

Durkheim, E. 1933. The division of labour in society. New York: Macmillan.

De Graaf, N. D. and H. D. Flap. 1988. With a little help from my friends: Social resources as an explanation of occupational status and income in West Germany, The Netherlands, and the United States. Social Forces 67(2): 452-472.

Flemming, J. 1984. Blacks in college. San Francisco: Jossey Bass.

Gould, R. V. and R. M. Fernandez. 1989. Structures of mediation: A formal approach to brokerage in transaction networks. Sociological Methodology 19: 89-126.

Granovetter, M. S. 1973. The strength of weak ties. American Journal of Sociology 78(6): 1360-1380.

Galeakiewicz, J. and K. R. Krohn. 1984. Positions, roles, and dependencies in a community interorganization system. The Sociological Quarterly 25(4): 527-550.

Ishitani, T. T. 2006. Studying attrition and degree completion behavior among first-generation college students in the United States. The Journal of Higher Education 77(5): 861-885.

Lara, J. 1992. Reflections: Bridging cultures. In First-generation students: Confronting the cultural issues. New directions for community colleges. No. 80, ed. L. Zwerling and H. London, 65-70. San Francisco: Jossey-Bass.

Lin, N. and Y. Bian. 1991. Getting ahead in urban China. American Journal of Sociology 97(3): 657688.

Lin, N. 1999. Building a network theory of social capital. Connections 22(1): 28-51.

Loo, C. M. and G. Rolison. 1986. Alienation of ethnic minority students at a predominantly white university. Journal of Higher Education 57(1): 58-77.

Marsden, P. V. 1982. Brokerage behavior in restricted exchange networks. Social Structure and Network Analysis 7(4): 341-410.

Marsden, P. V. and J. S. Hurlbert. 1988. Social resources and mobility outcomes: A replication and extension. Social Forces 66(4): 1038-1059.

Mayer, R. C., J. H. Davis and F. D. Schoorman. 1995, “An integrative model of organizational trust”. Academy of Management Review 20(3): 709-34.

McCarty, C., J. L. Molina, C. Aguilar and L. Rota. 2007. A comparison of social network mapping and personal network visualization. Field Methods 19(2): 145-162. DOI: 10.1177/1525822X06298592.

Nettles, M. T. 1991. Racial similarities and differences in the predictors of college student achievement. In College in black and white: African American students in predominantly white and in 
historically black Public Universities, ed. W. R. Allen, E. G. Epps and N. Z. Haniff, 75-94. Albany: State University of New York Press.

Pascarella, E. T., C. T. Pierson. G. C. Wolniak and P. T. Terenzini. 2004. First-generation college students: Additional evidence on college experiences and outcomes. The Journal of Higher Education 75(3): 249-284.

Perri 6. 1997. Holistic government. London: Demos.

Portes, A. and J. Sensenbrenner. 1993. Embeddedness and immigration: Notes on the social determinants of economic action. American Journal of Sociology 98(6): 1320-1350.

Putnam, R. D. 2000. Bowling alone: The collapse and revival of American community. New York: Simon \& Schuster Paperbacks.

Rendon, L. 1992. From the Barrio to the Academy: Revelations of a Mexican American "scholarship girl”. In First-generation students: Confronting the cultural issues. New directions for community colleges No. 80, ed. L. Zwerling and H. London, 55-64. San Francisco: Jossey-Bass.

Rendon, L. and R. Hope. (Eds.). 1996. Educating a new majority: Transforming America's education system for diversity. San Francisco: Jossey-Bass.

Rogers, E. M. 1995. Diffusion of innovations. $4^{\text {th }}$ Edition. The Free Press: New York.

Scott, I., N. Yeld and J. Hendry. 2007. A case for improving teaching and learning in South African higher education. Higher Education Monitor No. 6. Pretoria: Council on Higher Education. http://www.che.ac.za/ documents/d000155/index.php

Sennett, J., G. Finchilescu, K. Gibson and R. Strauss. 2003. Adjustment of black students at a historically white South African university. Education Psychology 23(1): 107-116.

Sprengers, M., F. Tazelaar and H. D. Flap. 1988. Social resources, situational constraints, and reemployment. Netherlands Journal of Social Sciences 24: 98-116.

Strydom, J. F., M. Mentz and G. D. Kuh. 2010. Enhancing success in higher education by measuring student engagement in South Africa. Acta Academica 42(1): 259-278

Terenzini, P., L. Rendon, M. Upcraft, J. Millar and A. Nora. 1994. The transition to college: Diverse students, diverse stories. Research in Higher Education 37(1): 1-22.

Volker, B. and H. Flap. 1996. Getting ahead in the GDR: Human capital and social capital in the status attainment process under communism. Universiteit Utrecht, The Netherlands.

Weis, L. 1992. Discordant voices in the Urban Community College. In First-generation students: Confronting the cultural issues. New directions for community colleges, No. 80., ed. L. Zwerling and H. London, 13-27. San Francisco: Jossey-Bass. 